\title{
Hypothalamic-pituitary-gonadal endocrine system in the hagfish
}

\section{Masumi Nozaki *}

Sado Marine Biological Station, Faculty of Science, Niigata University, Sado, Japan

Edited by:

Silvia Fasano, Second University of Naples, Italy

\section{Reviewed by:}

Rosanna Chianese, Second University of Naples, Italy

Rosaria Meccariello, University of Naples Parthenope, Italy

*Correspondence:

Masumi Nozaki, Sado Marine

Biological Station, Faculty of Science,

Niigata University, Tassha, Sado,

Niigata 952-2135, Japan

e-mail:nozaki@cc.niigata-u.ac.jp
The hypothalamic-pituitary system is considered to be a seminal event that emerged prior to or during the differentiation of the ancestral agnathans (jawless vertebrates). Hagfishes as one of the only two extant members of the class of agnathans are considered the most primitive vertebrates known, living or extinct. Accordingly, studies on their reproduction are important for understanding the evolution and phylogenetic aspects of the vertebrate reproductive endocrine system. In gnathostomes (jawed vertebrates), the hormones of the hypothalamus and pituitary have been extensively studied and shown to have well-defined roles in the control of reproduction. In hagfish, it was thought that they did not have the same neuroendocrine control of reproduction as gnathostomes, since it was not clear whether the hagfish pituitary gland contained tropic hormones of any kind. This review highlights the recent findings of the hypothalamic-pituitary-gonadal endocrine system in the hagfish. In contrast to gnathostomes that have two gonadotropins (GTH: luteinizing hormone and follicle-stimulating hormone), only one pituitary GTH has been identified in the hagfish. Immunohistochemical and functional studies confirmed that this hagfish GTH was significantly correlated with the developmental stages of the gonads and showed the presence of a steroid (estradiol) feedback system at the hypothalamic-pituitary levels. Moreover, while the identity of hypothalamic gonadotropin-releasing hormone $(\mathrm{GnRH})$ has not been determined, immunoreactive (ir) $\mathrm{GnRH}$ has been shown in the hagfish brain including seasonal changes of ir-GnRH corresponding to gonadal reproductive stages. In addition, a hagfish PQRFamide peptide was identified and shown to stimulate the expression of hagfish GTH $\beta$ mRNA in the hagfish pituitary. These findings provide evidence that there are neuroendocrine-pituitary hormones that share common structure and functional features compared to later evolved vertebrates.

Keywords: hagfish, agnathan, cyclostomes, HPG axis, pituitary gland, gonadotropin, GnRH, estradiol

\section{INTRODUCTION}

Reproduction in gnathostomes (jawed vertebrates) is controlled by a hierarchically organized endocrine system called the hypothalamic-pituitary-gonadal (HPG) axis (1). In spite of the diverged patterns of reproductive strategies and behaviors within this taxon, this endocrine network is remarkably conserved throughout gnathostomes. In response to hypothalamic gonadotropin-releasing hormone $(\mathrm{GnRH})$, gonadotropins (GTHs) are secreted from the pituitary and stimulate the gonads, where they induce the synthesis and release of sex steroid hormones, which in turn elicit growth and maturation of the gonads (Figure 1).

The pituitary gland is present in all vertebrates from agnathans (jawless fishes) to mammals and consists of the same two principal elements, the neurohypophysis and adenohypophysis. The neurohypophysis develops from the floor of the diencephalon as an infundibular extension, whereas the adenohypophysis develops from the epithelium that comes in contact with this infundibulum. The enigma of the pituitary gland is that evolution of a composite organ with such a complex double developmental origin must have been associated with some functionally adaptive value.
Yet demonstration of this adaptive value in the agnathans themselves remains elusive. Most surprising facts are that not only the pituitary gland but also all major adenohypophysial hormones such as GTHs, growth hormone (GH), prolactin, and adrenocorticotropin (ACTH) and their receptors are also considered to be vertebrate novelties (2). Thus, the hypothalamic-pituitary system, which is specific to vertebrates, is considered to be a seminal event that emerged prior to or during the differentiation of the ancestral agnathans. Such an evolutionary innovation is one of the key elements leading to physiological divergence, including reproduction, growth, metabolism, stress, and osmoregulation in subsequent evolution of gnathostomes.

Lampreys and hagfish are the only two extant representatives of agnathans. Paleontological analysis of extinct agnathans had suggested that lampreys were more closely related to gnathostomes than either group is to the hagfishes $(3,4)$. However, both recent molecular phylogenetic analyses (5-7) and developmental study on the craniofacial pattern of the hagfish (8) strongly support the monophyly of the cyclostomes (lampreys and hagfishes as closest relatives). Therefore, studies on reproduction of the cyclostomes are important for understanding the evolution of the HPG axis 


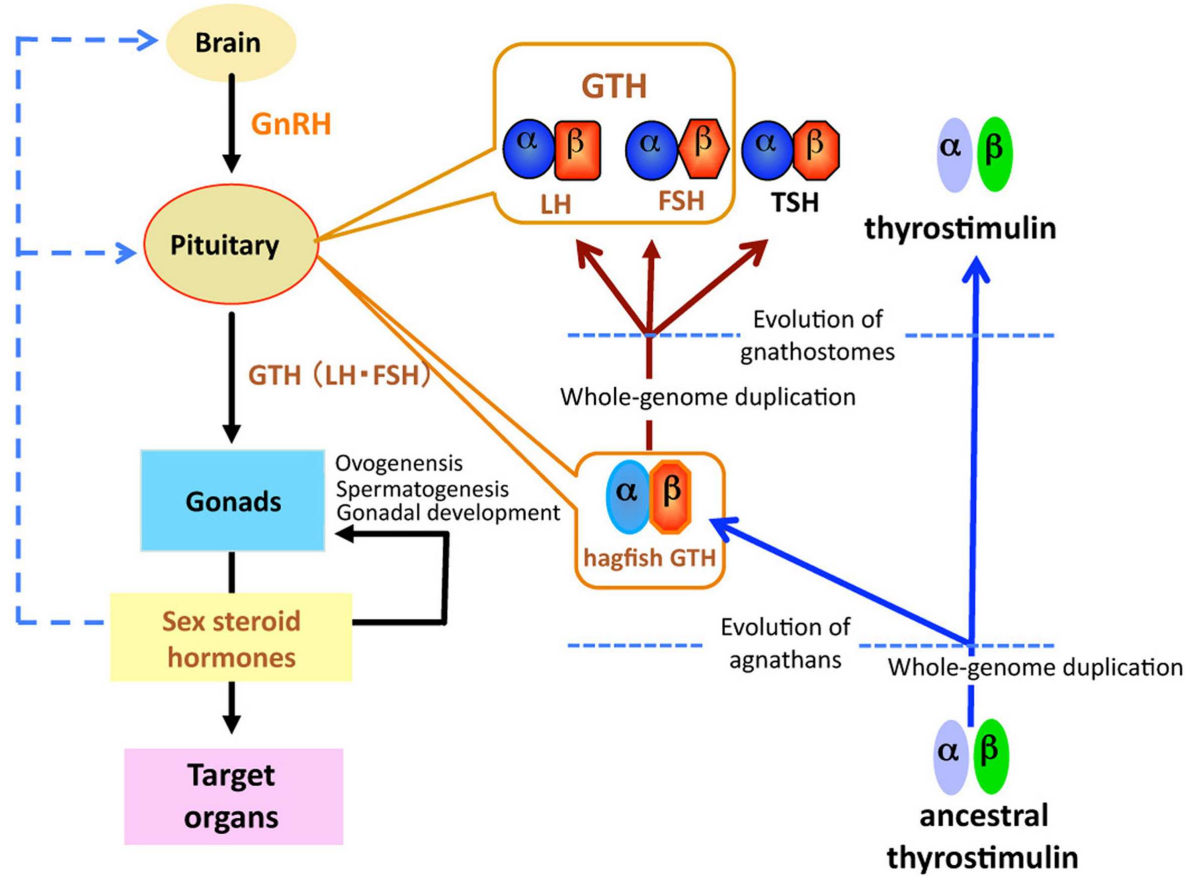

FIGURE 1 | Schematic diagram of the evolution of glycoprotein hormones in the hypothalamic-pituitary-gonadal axis. Ancestral thyrostimulin ( $\alpha$ and $\beta$ ) existed before divergence of vertebrates. An ancestral thyrostimulin ( $\alpha$ and $\beta$ ) diverged into GTH ( $\alpha$ and $\beta$ ) and thyrostimulin ( $\alpha$ and $\beta$ ) during the early phase of agnathan divergence. The GTH ( $\alpha$ and $\beta$ ) formed a heterodimer in the pituitary and acted as the first adenohypophysial gonadotropic hormone during the evolution of agnathan species. This GTH dimer further diverged into three functional units of adenohypophysis, LH and $\mathrm{FSH}$ as two gonadotropins, and TSH as a thyrotropin, in the lineage to gnathostomes. related to vertebrate reproduction. Findings from many molecular, biochemical, physiological, and morphological studies indicate that the HPG axis is present in the lamprey [for review, see Ref. (1)]. In contrast, endocrine regulation of reproduction in the hagfish is poorly understood [for reviews, see Ref. $(9,10)$ ]. For example, until the recent identification of functional GTH in the brown hagfish, Paramyxine atami (11), it was not established whether the hagfish pituitary gland contains tropic hormones of any kind. Herein, this report summarizes the recent findings of the HPG endocrine system involved in reproduction in hagfish.

\section{HAGFISH PITUITARY GLAND}

The hagfish is considered the most primitive vertebrate known, living or extinct (3) (Figure 2). In addition to their primitive external body features, hagfish possess the most primitive hypothalamicpituitary system among the vertebrates (12). The neurohypophysis is a flattened sac-like structure, whereas the adenohypophysis consists of a mass of clusters of cells embedded in connective tissue below the neurohypophysis $(12,13)$ (Figures 3A,B). The adenohypophysis and the neurohypophysis are completely separated by a layer of connective tissue, and there is no or little anatomical relationship between them $(14,15)$ (Figure 3B). In addition, there is no clear cytological differentiation between the pars distalis and the pars intermedia $(12,13)$ (Figure 3B). The question arises whether the simplicity of the hagfish pituitary gland is a primitive or a degenerate feature. For example, some authors have claimed that the pars intermedia seems to have been lost via a secondary degenerative process $(13,16)$. Moreover, until recent identification of a functional GTH in the hagfish pituitary (11), it had not been established whether the hagfish pituitary gland contained adenohypophysial hormones of any kind (9). Because of the simplicity and primitiveness of the pituitary morphology and equivocal data on the adenohypophysial hormones in the hagfish, many researchers had questioned whether there were any functional adenohypophysial hormones $(9,17)$. On the other hand, arginine vasotocin (AVT), as a single neurohypophysial hormone, was identified in the hagfish (18). In addition, the presence of $\mathrm{GnRH}$ has been suggested in the hagfish hypothalamus by both radioimmunoassay (RIA) and immunohistochemistry (19-22) (Figure 4). Thus, the hagfish appears to have neurohypophysial and hypothalamic hormones similar to those of other vertebrates.

At present, the adenohypophysis of the hagfish is the least understood of all the vertebrates. However, our immunohistochemical studies provided the first clear-cut evidence for the presence of GTH and ACTH in the hagfish (23-25). Although not conclusive, our data also suggested the presence of GH in the hagfish (23). In addition, these three adenohypophysial hormones were suggested to be the ancestral adenohypophysial hormones that have maintained their original functions throughout vertebrate evolution. On the other hand, the later derived hormones, such as prolactin and thyroid-stimulating hormone (TSH), may have contributed to the expansion of vertebrates into new environments, as suggested by Kawauchi et al. (26) and Kawauchi and Sower (27). Moreover, our study further revealed that GTH 
cells, ACTH cells, and unidentified cells which were assumed to include both undifferentiated cells and GH cells, were packed together in the same cell cluster of the hagfish adenohypophysis, and thus each cluster appeared to serve as a separate functional unit $(10,24)$ (Figures 3C-E). If the absence of the pars intermedia is the most ancestral vertebrate pituitary gland, melanophorestimulating hormone (MSH) activity seems to be gained secondarily together with the differentiation of the pars intermedia. Further studies are needed to clarify this possibility.

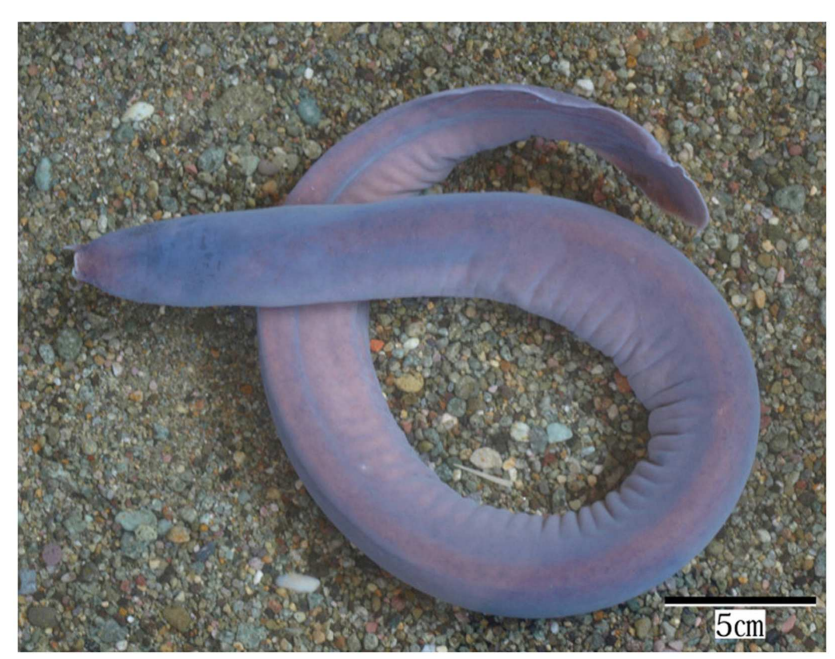

FIGURE 2 | Brown hagfish, Paramyxine atami

A

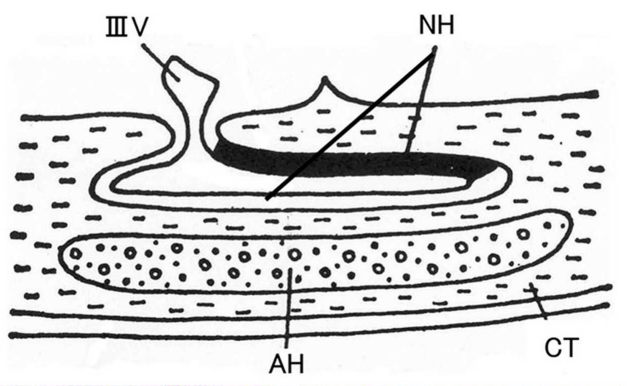

FIGURE 3 | (A) Diagrammatically sagittal section of the hagfish pituitary gland. Dark area of the neurohypophysis $(\mathrm{NH})$ shows posterior part of the dorsal wall, where ir-GnRH nerve fibers and AVT nerve fibers are densely accumulated [for AVT, see Ref. (82)]. (B) Nearly mid-sagittal section of the pituitary gland of the brown hagfish, stained with hematoxylin and eosin. (C,D) GTH $\beta$-like immunoreaction in the adenohypophysis of the juvenile (C) and sexually mature (D) brown hagfish stained with

\section{GLYCOPROTEIN HORMONE FAMILY}

Gonadotropins, in response to hypothalamic $\mathrm{GnRH}$, are released from the pituitary and act on the gonads to regulate steroidogenesis and gametogenesis. Two GTHs, follicle-stimulating hormone (FSH) and luteinizing hormone (LH), together with TSH form a family of pituitary hormones (Figure 1). They are heterodimeric glycoproteins consisting of two subunits, an $\alpha$-subunit and a unique $\beta$-subunit. These glycoprotein hormones (GPH) are believed to have evolved from a common ancestral molecule through duplication of $\beta$-subunit genes and subsequent divergence $(27,28)$. Two GTHs have been identified in all taxonomic groups of gnathostomes, including actinopterygians (29, 30), sarcopterygians (31), and chondrichthyans (32), but not in agnathans.

A single $\beta$-subunit of GTH was identified from the sea lamprey pituitary gland after extensive and exhaustive research for over 20 years $(27,33)$. However, the $\alpha$-subunit of lamprey GTH is not found even in the lamprey genome (34). This is very strange fact, since a huge amount of physiological and morphological evidence has suggested the presence of GTH in the lamprey $(33,35-38)$. The lack of $\alpha$-subunit of lamprey GTH makes difficulty to study the HPG axis in relation to GTH functions in the lamprey. The second form of $\beta$-subunit of pituitary GPHs as a candidate for TSH $\beta$ is not found in the lamprey genome (34), and thus the lamprey does not have TSH.

Recently, a fourth heterodimeric GPH has been discovered in the human genome and termed "thyrostimulin" due to its thyroid-stimulating activity (39). The thyrostimulin $\alpha$-subunit, called glycoprotein $\alpha$-subunit 2 (GPA2), is homologous but not identical to the common $\alpha$-subunit (GPH $\alpha$ or GPA1). With the
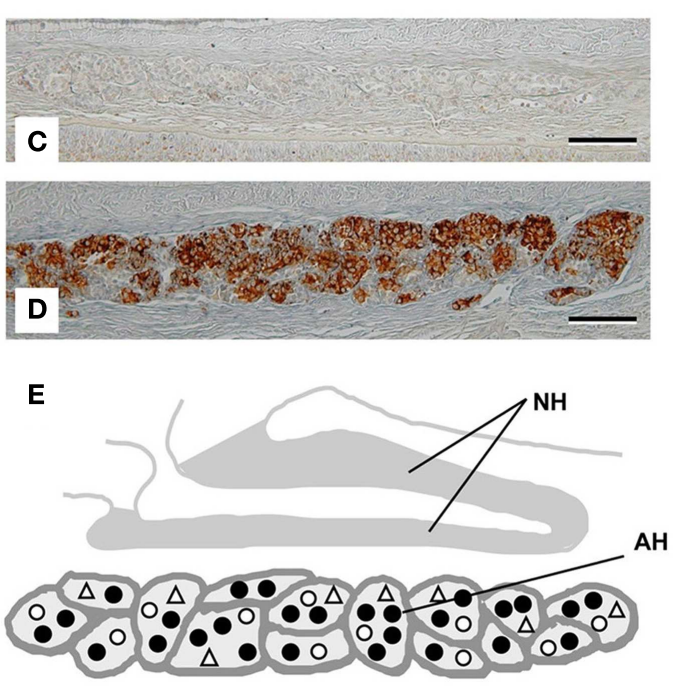

anti-hagfish GTH $\beta$. Note that GTH-positive cells are almost absent in (C), whereas they are abundant in (D). (E), Diagrammatically sagittal section of the hagfish pituitary gland showing the topographic distribution of adenohypophysial cells. Closed circle, GTH cell; open circle, ACTH cell; open triangle, undifferentiated cell and possible $\mathrm{GH}$ cell. $\mathrm{AH}$, adenohypophysis; $\mathrm{CT}$, connective tissue; IIIV, third ventricle. Scale bars: $100 \mu \mathrm{m}$. 


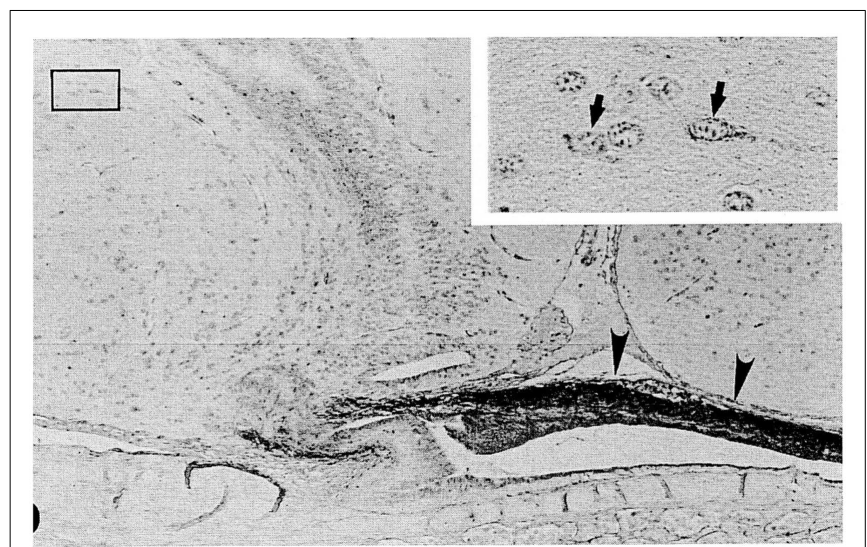

FIGURE 4 | A nearly mid-sagittal section through the neurohypophysis of the Atlantic hagfish, Myxine glutinosa, showing the accumulation of ir-GnRH in the dorsal wall of the neurohypophysis (arrowheads).

This section was stained with anti-salmon $\mathrm{GnRH}$. Inset, an enlargement of the rectangular area showing $\mathrm{GnRH}$-positive neuronal cells. Arrows show $\mathrm{GnRH}$-positive cell bodies. Scale bars: $100 \mu \mathrm{m}$; inset, $20 \mu \mathrm{m}$. From Oshima et al. (21).

discovery of GPA2 and glycoprotein $\beta$-subunit 5 (GPB5, thyrostimulin beta) homologs not only in other vertebrates but invertebrates including fly, nematode, and sea urchin $(40,41)$, it is proposed that ancestral glycoprotein existed before the divergence of vertebrates/invertebrates, and that later gene duplication events in vertebrates produced the thyrostimulin (GPA2 and GPB5) and GTH/TSH [GPH $\alpha$ and GPH $\beta$ ( $\mathrm{LH} \beta / \mathrm{FSH} \beta / \mathrm{TSH} \beta)]$ (40) (Figure 1). The basal lineage of chordates such as tunicates and amphioxus contains GPA2 and GPA5 in their genome but not GPH $\alpha$ or GPH $\beta(2,42-45)$. Lamprey also has GPA2 and GPB5 genes in addition to the canonical $\operatorname{GTH} \beta(1,33,34,42)$. At present, no information is available as to the presence of GPA2/GPB5 in the hagfish.

\section{IDENTIFICATION OF HAGFISH GTH}

A single GPH, which comprises $\alpha$ - and $\beta$-subunits, was recently identified in the pituitary of the brown hagfish, $P$. atami, one of the Pacific hagfish (11) (Figure 2). Both subunits of GPH are produced in the same cells of the adenohypophysis, providing definitive evidence for the presence of a heterodimeric GPH in the hagfish. $\mathrm{GPH}$ increases at both the gene and protein levels corresponding to the reproductive stages of the hagfish (Figures 3C,D). Moreover, purified native GPH induces sex steroid release (estradiol-17 $\beta$ and testosterone) from cultured testis in a dose-dependent manner. From the phylogenetic analysis, the hagfish GPH $\alpha$ forms a clade with the gnathostome GPH $\alpha$ s. The hagfish GPH $\beta$ forms a clade with the TSH $\beta$ s, however the bootstrap values are low and hagfishes evolved prior to the gnathostomes. The sea lamprey GTH $\beta$ also groups with the GPH $\beta$ s but appears to be one of the outgroups of the LH $\beta$ s. These results clearly show that the GPH identified in the hagfish acts as a functional gonadotropin, and hereafter it is referred as to GTH. Hagfish GTH is the earliest evolved pituitary GPH that has been identified in a basal vertebrate leading to the gnathostome GTH and TSH lineages.

\section{FEEDBACK REGULATION OF HAGFISH GTH SYNTHESIS AND} SECRETION

Gonadal steroid hormones and hypothalamic hormones play major roles in controlling the synthesis and release of $\mathrm{LH}$ and FSH in gnathostomes. Both positive and negative feedback effects of gonadal steroids have been demonstrated in teleosts, depending on modes of administration and reproductive stages of animals. In general, in sexually mature fish, sex steroids are considered to regulate gonadal maturation and recrudesce, whereas in juvenile fish, sex steroids are considered to regulate puberty. Thus, negative feedback effects of estradiol and testosterone are evident during the latter stages of gonadal development; specifically, it has been shown that gonadal removal increases LH secretion in salmon (46), goldfish (47), and African catfish (48). The observed increases in LH levels can be suppressed by treatment with estradiol, testosterone, or both. FSH is also controlled by steroid-dependent negative feedback loops in rainbow trout (49), salmon (50), and goldfish (51). The negative feedback effects of steroids may be mediated primarily at the levels of the hypothalamic GnRH neurons (52-54), because both in vivo and in vitro studies have shown that the expression of LH $\beta$ mRNA or FSH $\beta$ mRNA is often unchanged or increases following exposure to estradiol, testosterone, or both (49, $53,55)$. However, in sexually immature teleosts, sex steroids appear to exert primarily a positive feedback effect that acts directly at the level of the pituitary and via effects on the GnRH system (55, 56). LH content and LH mRNA levels of the pituitary in juvenile fish increase in response to estrogens and aromatizable androgens $(49,57)$.

Estradiol treatment in the juvenile brown hagfish resulted in the marked accumulation of both immunoreactive (ir)-GTH $\alpha$ and ir-GTH $\beta$ in the pituitary (58). However, mRNA levels of GTH $\alpha$ and GTH $\beta$ in the pituitary were not, or only transiently, increased by the estradiol treatment (58). The latter results suggest that syntheses of both $\alpha$ - and $\beta$-subunits of GTH were not, or only transiently, affected by the estradiol treatment. Accordingly, the marked accumulation of both ir-GTH subunits could be attributed to the suppression of GTH secretion from the pituitary. From that study, the feedback effects of estradiol appeared to be inhibitory rather than stimulatory, and mediated by the possible suppression of the secretion of GTH from the pituitary in these juvenile hagfish. These conditions in juvenile hagfish resembled to those in adults, but not in juveniles, of teleosts $(49,53,55)$. Such suppression of GTH secretion in the hagfish is probably regulated by the hypothalamic factors including $\mathrm{GnRH}$, as mentioned below.

On the other hand, testosterone treatment in the juvenile brown hagfish had no effect on the staining intensities of the ir-GTH $\alpha$ and ir-GTH $\beta$ in the pituitary (58). Nevertheless, testosterone treatment resulted in the suppression of mRNA expressions of both GTH $\alpha$ and GTH $\beta$ in the pituitary (58). Therefore, testosterone probably acts to suppress both the synthesis and the secretion of GTH. This conclusion follows from the reasoning that if the secretion of GTH was not suppressed, the intensities of immunoreactions of both GTH $\alpha$ and GTH $\beta$ would have decreased due to decreased levels of mRNA expressions of both GTH subunits. Thus, it seems likely that estradiol and testosterone differ with regard to their roles in the regulation of synthesis and secretion of GTH in the pituitary of the hagfish. 


\section{PLASMA LEVELS OF SEX STEROID HORMONES IN THE HAGFISH}

Only a few studies exist regarding sex steroid hormonal profiles in relation to gonadal function in hagfish. Matty et al. (17) reported that estradiol and testosterone were measurable in the plasma of Eptatretus stouti using RIA; however, the observed levels of these steroids were near the lower limit of RIA sensitivity. Schützinger et al. (59) found using a more sensitive RIA that plasma estradiol content increased in relation to the stages of ovarian development in female Atlantic hagfish, Myxine glutinosa. Powell et al. $(60,61)$ also reported using in vitro organ cultured ovaries that the number of females with large eggs increased following estradiol peaks in January in M. glutinosa. Thus, estrogen seems to be involved in the ovarian development.

Plasma concentrations of estradiol, testosterone, and progesterone were examined with respect to gonadal development, sexual differences, and possible function of atretic follicles in the brown hagfish, P. atami, using a time-resolved fluoroimmunoassay (62). In females, plasma estradiol levels showed a significant positive correlation with ovarian development, while plasma testosterone and progesterone levels were highest in non-vitellogenic adults (62). Thus, our data on plasma estradiol levels in female P. atami were consistent with the results of Schützinger et al. (59) and Powell et al. (60). In another study, Yu et al. (63) demonstrated that the synthesis of hepatic vitellogenin was inducible by estrogens, estradiol, and estrone, in E. stouti. Based on these results, estrogenic control of ovarian development and hepatic vitellogenesis seemed to have arisen early in vertebrate evolution.

In males, no clear relationships were observed between plasma estradiol or testosterone concentrations and testicular development, while plasma progesterone concentrations showed a significant inverse relationship with testicular development (62). However, in that study data on sexually mature males with high incidences of spermatids or spermatozoa were lacking, since they were very few in our populations (62). Therefore, it is still possible to consider that estradiol and testosterone are involved in the regulation of male reproduction in hagfish. In support of this possibility, it is reported that purified native hagfish GTH induced secretion of estradiol and testosterone from cultured hagfish testes (11). Moreover, intraperitoneal administration of these steroids in juvenile hagfish affected on the GTH functions as mentioned above.

On the other hand, in relation to our failure to correlate plasma concentrations of estradiol or testosterone to testicular development, recent studies in the lamprey have emphasized the importance of non-classical steroids, such as androstenedione and $15 \alpha$-hydroxylated sex steroids ( $15 \alpha$-hydroxytestosterone and 15 $\alpha$ hydroxyprogesterone) in serving as functional androgens (6467). Indeed, evidence demonstrating testosterone functionality in lampreys was scarce [see Ref. (68)], while androstenedione was found in substantial amounts within the testicular tissue of lampreys, and plasma and tissue levels of the hormone increased significantly in prespermiating male sea lampreys after injection of GnRH (66). In addition, prespermiating males implanted with androstenedione reached maturation significantly faster and exhibited larger secondary sex characteristics than placebo or nonimplanted males (66). A receptor for androstenedione was recently described by Bryan et al. (66). 15 $\alpha$-Hydroxylated steroids are also suggested to be involved in the regulation of lamprey reproduction (67). Since hagfish gonads also produce substantial amounts of unusual androgens, such as $6 \beta$-hydroxy testosterone and $5 \alpha$ androstane-3 $\beta, 7 \alpha, 17 \beta$-triol, as well as androstenedione (69-71), some of these steroids may act as functional androgens in the hagfish.

\section{HYPOTHALAMIC FACTORS REGULATING THE GONADOTROPIC FUNCTION OF HAGFISH}

The synthesis and secretion of GnRH is the key neuroendocrine function in the hypothalamic regulation of the HPG axis. To date, two to three isoforms have been identified in representative species of all classes of gnathostomes and lampreys (1). GnRHs are also identified in tunicates (72), and several invertebrates belonging to lophotrochozoans [mollusk and annelid; $(73,74)$ ], but not in the ecdysozoan lineages. On the other hand, adipokinetic hormone (AKH) has been identified as the ligand of the GnRH receptor of the insects, Drosophila and Bombyx (75). An AKH-GnRH-like neuropeptide has been identified in the nematode C. elegans (76). A comparative and phylogenetic approach shows that the ecdysozoan AKHs, lophotrochozoan GnRHs, and chordate GnRHs are structurally related and suggested that they all originate from a common ancestor (77).

In the hagfish, GnRH has not yet been identified, but previous chromatographic and immunohistochemical studies have suggested the presence of a GnRH-like molecule in the hypothalamicneurohypophysial area $(19,20)$. Kavanaugh et al. (22) reported the seasonal changes in hypothalamic ir-GnRH contents in relation gonadal reproductive stages in the Atlantic hagfish (M. glutinosa). In M. glutinosa, a dense accumulation of GnRH-like immunoreaction was observed in the dorsal wall of the neurohypophysis with the use of antisera against chicken GnRH-II, salmon GnRH, lamprey GnRH-I, and lamprey GnRH-III $(19,21)$ (Figure 4). Neuronal cells containing ir-GnRH were found in the preoptic nucleus and the dorsal hypothalamic nucleus $(20,21)$. In another study, Osugi et al. (78) identified several PQRFamide peptides in the brain of the brown hagfish (P. atami). Based on in situ hybridization and immunohistochemistry, hagfish PQRFamide peptide precursor mRNA and its translated peptides were localized in the infundibular nucleus of the hypothalamus. Dense ir fibers were found in the infundibular nucleus and some of them were terminated on blood vessels within the infundibular nucleus. They further showed that one of the hagfish PQRFamide peptides significantly stimulated the expression of GTH $\beta$ mRNA in the cultured hagfish pituitary. The latter result clearly indicates that GTH functions of the hagfish pituitary are controlled by the hypothalamic factors.

Puzzling aspect of the hagfish hypothalamic-pituitary system is that there is no or little anatomical relationship between them. It is generally considered that the hypothalamic factors, such as GnRH, reach the adenohypophysis simply by diffusion $(79,80)$. However, the dorsal wall of the hagfish neurohypophysis, where ir-GnRH nerve fibers are terminated (Figure 4), is far from the adenohypophysis by the presence of the neurohypophysis itself. On the other hand, the blood vessels are richly distributed on the surface of the dorsal wall, and make the posterior hypophysial vascular 
plexus $(14,15)$. Although most blood in the posterior hypophysial vascular plexus enter the posterior hypophysial vein of the anterior cardinal system, several small vessels proceed from the dorsal wall to the adenohypophysis in Eptatretus burgeri (15). These small vessels may contribute the regulation of the adenohypophysial functions. A pair of small blood vessels from the hypothalamus also enters the posterior hypophysial vascular plexus (14). Together with the fact that some PQRFamide neuronal fibers terminated on the blood vessels within the hypothalamus (78), further studies are needed to understand the hypothalamic-pituitary system of the hagfish.

\section{CONCLUSION}

Not only the pituitary gland but also all major adenohypophysial hormones and their receptors are considered to be vertebrate novelties. Since hagfish represent the most basal and primitive vertebrate that diverged over 550 millions years ago (81), they are of particular importance in understanding the evolution of the HPG axis related to vertebrate reproduction. Our data clearly show that the hagfish has a functional HPG axis similar to that of more advanced gnathostomes. It is strongly expected that the functional GTH found in hagfish pituitary helps to delineate the evolution of the complex HPG axis of reproduction in vertebrates. Furthermore, this HPG system likely evolved from an ancestral, pre-vertebrate exclusively neuroendocrine mechanism by gradual emergence of components of a new control level, the pituitary gland.

\section{ACKNOWLEDGMENTS}

I would like to express my gratitude to Professor Stacia A. Sower, University of New Hampshire, USA for her kindness in reading the manuscript. This work was supported in parts by Grant-in Aid for Basic Research and by Japanese Association for Marine Biology (JAMBIO) from Ministry of Education, Culture, Sports, Science, and Technology (MEXT), Japan.

\section{REFERENCES}

1. Sower SA, Freamat M, Kavanaugh SI. The origins of the vertebrate hypothalamic-pituitary-gonadal (HPG) and hypothalamic-pituitary-thyroid (HPT) endocrine systems: new insights from lampreys. Gen Comp Endocrinol (2009) 161:20-9. doi:10.1016/j.ygcen.2008.11.023

2. Holland LZ, Albalat R, Azumi K, Benito-Gutiérrez È, Blow MJ, Bronner-Fraser $\mathrm{M}$, et al. The amphioxus genome illustrates vertebrate origins and cephalochordate biology. Genome Res (2008) 18:1100-11. doi:10.1101/gr.073676.107

3. Forey P, Janvier P. Agnathans and the origin of jawed vertebrates. Nature (1993) 361:129-34. doi:10.1038/361129a0

4. Forey P, Janvier P. Evolution of the early vertebrates. Am Sci (1994) 82:554-66.

5. Delarbre C, Gallut C, Barriel V, Janvier P, Gachelin G. Complete mitochondrial DNA of the hagfish, Eptatretus burgeri: the comparative analysis of mitochondrial DNA sequences strongly supports the cyclostome monophyly. Mol Phylogenet Evol (2002) 22:184-92. doi:10.1006/mpev.2001.1045

6. Takezaki N, Figueroa F, Zaleska-Rutczynska Z, Klein J. Molecular phylogeny of early vertebrates: monophyly of the agnathans as revealed by sequences of 35 genes. Mol Biol Evol (2003) 20:287-92. doi:10.1093/molbev/msg040

7. Heimberg AM, Cowper-Sal-Iari R, Semon M, Donoghue P, Peterson KJ. microRNAs reveal the interrelationships of hagfish, lampreys, and gnathostomes and the nature of the ancestral vertebrate. Proc Natl Acad Sci USA (2010) 107:19379-83. doi:10.1073/pnas.1010350107

8. Oisi Y, Ota KG, Kuraku S, Fujimoto S, Kuratani S. Craniofacial development of hagfishes and the evolution of vertebrates. Nature (2013) 493:175-80. doi:10.1038/nature11794
9. Gorbman A. Reproduction in cyclostome fishes and its regulation. In: Hoar WS, Randall DJ editors. Fish Physiology. (Vol. IXA), New York: Academic Press (1983). p. 1-28.

10. Nozaki M. The hagfish pituitary gland and its putative adenohypophysial hormones. Zoolog Sci (2008) 25:1028-36. doi:10.2108/zsj.25.1028

11. Uchida K, Moriyama S, Chiba H, Shimotani T, Honda K, Miki M, et al. Evolutionary origin of a functional gonadotropin in the pituitary of the most primitive vertebrate, hagfish. Proc Natl Acad Sci U S A (2010) 107:15832-7. doi:10.1073/pnas.1002208107

12. Holmes RL, Ball JN. The Pituitary Gland, A Comparative Account. London: Cambridge University Press (1974).

13. Hardisty MW. Biology of Cyclostomes. London: Chapman and Hall (1979).

14. Gorbman A, Kobayashi H, Uemura H. The vascularisation of the hypophysial structure of the hagfish. Gen Comp Endocrinol (1963) 3:505-14. doi:10.1016/ 0016-6480(63)90083-2

15. Kobayashi H, Uemura H. The neurohypophysis of the hagfish, Eptatretus burgeri (Girard). Gen Comp Endocrinol (1972) 3:114-24. doi:10.1016/0016-6480(72) 90139-6

16. Gorbman A, Dickhoff WW, Vigna SR, Clark NB, Ralph CL. Comparative Endocrinology. New York: John Wiley \& Sons (1983).

17. Matty AJ, Tsuneki K, Dickhoff WW, Gorbman A. Thyroid and gonadal function in hypophysectomized hagfish, Eptatretus stouti. Gen Comp Endocrinol (1976) 30:500-16. doi:10.1016/0016-6480(76)90120-9

18. Suzuki M, Kubokawa M, Nagasawa K, Urano A. Sequence analysis of vasotocin cDNAs of the lamprey, Lampetra japonica and the hagfish Eptatretus burgerievolution of cyclostome vasotocin precursors. J Mol Endocrinol (1995) 14:67-77. doi:10.1677/jme.0.0140067

19. Sower SA, Nozaki M, Knox CJ, Gorbman A. The occurrence and distribution of GnRH in the brain of Atlantic hagfish, an Agnathan, determined by chromatography and immunocytochemistry. Gen Comp Endocrinol (1995) 97:300-7. doi:10.1006/gcen.1995.1030

20. Braun CB, Wicht H, Northcutt RG. Distribution of gonadotropin-releasing hormone immunoreactivity in the brain of the Pacific hagfish Eptatretus stouti (Craniata, Myxinoidea). J Comp Neurol (1995) 353:464-76. doi:10.1002/cne. 903530313

21. Oshima Y, Ominato K, Nozaki M. Distribution of GnRH-like immunoreactivity in the brain of lampreys and hagfish. Annual Activity Reports of the Sado Marine Biological Station, Niigata University, No. 31. Sado: Daiichi Press (2001). p. 4-5.

22. Kavanaugh SI, Powell ML, Sower SA. Seasonal changes of gonadotropinreleasing hormone in the Atlantic hagfish Myxine glutinosa. Gen Comp Endocrinol (2005) 140:136-43. doi:10.1016/j.ygcen.2004.10.015

23. Nozaki M, Oshima Y, Miki M, Shimotani T, Kawauchi H, Sower SA. Distribution of immunoreactive adenohypophysial cell types in the pituitaries of the Atlantic and the Pacific hagfish, Myxine glutinosa and Eptatretus burgeri. Gen Comp Endocrinol (2005) 143:142-50. doi:10.1016/j.ygcen.2005.03.002

24. Nozaki M, Shimotani T, Uchida K. Gonadotropin-like and adrenocorticotropinlike cells in the pituitary gland of hagfish, Paramyxine atami: immunohistochemistry in combination with lectin histochemistry. Cell Tissue Res (2007) 328:563-72. doi:10.1007/s00441-006-0349-3

25. Miki M, Shimotani T, Uchida K, Hirano S, Nozaki M. Immunohistochemical detection of gonadotropin-like material in the pituitary of brown hagfish (Paramyxine atami) correlated with their gonadal functions and effect of estrogen treatment. Gen Comp Endocrinol (2006) 148:15-21. doi:10.1016/j.ygcen. 2006.01.018

26. Kawauchi H, Suzuki K, Yamazaki T, Moriyama S, Nozaki M, Yamaguchi K, et al. Identification of growth hormone in the sea lamprey, an extant representative of a group of the most ancient vertebrates. Endocrinology (2002) 143:4916-21. doi:10.1210/en.2002-220810

27. Kawauchi H, Sower SA. The dawn and evolution of hormones in the adenohypophysis. Gen Comp Endocrinol (2006) 148:3-14. doi:10.1016/j.ygcen.2005.10. 011

28. Dayhoff MO. Atlas of Protein Sequence and Structure. Silver Springs, MD: National Biomedical Research Foundation (1976).

29. Kawauchi H, Suzuki K, Itoh H, Swanson P, Naito N, Nagahama Y, et al. The duality of teleost gonadotropins. Fish Physiol Biochem (1989) 7:29-38. doi:10.1007/BF00004687

30. Quérat B, Sellouk A, Salmon C. Phylogenetic analysis of the vertebrate glycoprotein hormone family including new sequences of sturgeon (Acipenser baeri) 
beta subunits of the two gonadotropins and the thyroid-stimulating hormone. Biol Reprod (2000) 63:222-8. doi:10.1095/biolreprod63.1.222

31. Quérat B, Arai Y, Henry A, Akama Y, Longhurst TJ, Joss JM. Pituitary glycoprotein hormone beta subunits in the Australian lungfish and estimation of the relative evolution rate of these subunits within vertebrates. Biol Reprod (2004) 70:356-63. doi:10.1095/biolreprod.103.022004

32. Quérat B, Tonnerre-Donicarli C, Géniès F, Salmon C. Duality of gonadotropins in gnathostomes. Gen Comp Endocrinol (2001) 124:308-14. doi:10.1006/gcen. 2001.7715

33. Sower SA, Moriyama S, Kasahara M, Takahashi A, Nozaki M, Uchida K, et al. Identification of sea lamprey GTHbeta-like cDNA and its evolutionary implications. Gen Comp Endocrinol (2006) 148:22-32. doi:10.1016/j.ygcen.2005.11.009

34. Decatur WA, Hall JA, Smith JJ, Li W, Sower SA. Insight from the lamprey genome: glimpsing early vertebrate development via neuroendocrine-associated genes and shared synteny of gonadotropin-releasing hormone (GnRH). Gen Comp Endocrinol (2013) 192:237-45. doi:10.1016/j.ygcen.2013.05.020

35. Larsen LO, Rothwell B. Adenohypophysis. In: Hardisty MW, Potter IC editors. The Biology of Lampreys. (Vol. 2), London: Academic Press (1972). p. 1-67.

36. Hardisty MW, Baker BI. Endocrinology of lampreys. In: Hardisty MW, Potter IC editors. The Biology of Lampreys. London: Academic Press (1982). p. 1-115.

37. Sower SA. Brain and pituitary hormones of lampreys, recent findings and their evolutionary significance. Am Zool (1998) 38:15-38.

38. Nozaki M, Ominato K, Shimotani T, Kawauchi H, Youson JH, Sower SA. Identity and distribution of immunoreactive adenohypophysial cells in the pituitary during the life cycle of sea lampreys, Petromyzon marinus. Gen Comp Endocrinol (2008) 155:403-12. doi:10.1016/j.ygcen.2007.07.012

39. Nakabayashi K, Matsumi H, Bhalla A, Bae J, Mosselman S, Hsu SY, et al. Thyrostimulin, a heterodimer of two new human glycoprotein hormone subunits, activates the thyroid-stimulating hormone receptor. J Clin Invest (2002) 109:1445-52. doi:10.1172/JCI14340

40. Sudo S, Kuwabara Y, Park JI, Hsu SY, Hsueh AJ. Heterodimeric fly glycoprotein hormone-alpha2 (GPA2) and glycoprotein hormone-beta5 (GPB5) activate fly leucine-rich repeat-containing G protein-coupled receptor-1 (DLGR1) and stimulation of human thyrotropin receptors by chimeric fly GPA2 and human GPB5. Endocrinology (2005) 146:3596-604. doi:10.1210/en.2005-0317

41. Park J-II, Semeyonov J, Cheng CL, Hsu SYT. Conservation of the heterodimeric glycoprotein hormone subunit family proteins and the LGR signaling system from nematodes to humans. Endocrine (2005) 26:267-76. doi:10.1385/ENDO: 26:3:267

42. Dos Santos S, Bardet C, Bertrand S, Escriva H, Habert D, Querat B. Distinct expression patterns of glycoprotein hormone- $\alpha 2$ (GPA2) and $-\beta 5$ (GPB5) in a basal chordate suggest independent developmental functions. Endocrinology (2009) 150:3815-22. doi:10.1210/en.2008-1743

43. Dos Santos S, Mazan S, Venkatesh B, Cohen-Tannoudji J, Querat B. Emergence and evolution of the glycoprotein hormone and neurotrophin gene families in vertebrates. BMC Evol Biol (2011) 11:332. doi:10.1186/1471-2148-11-332

44. Tando Y, Kubokawa K. Expression of the gene for ancestral glycoprotein hormone beta subunit in the nerve cord of amphioxus. Gen Comp Endocrinol (2009) 162:329-39. doi:10.1016/j.ygcen.2009.04.015

45. Tando Y, Kubokawa K. A homolog of the vertebrate thyrostimulin glycoprotein hormone a subunit (GPA2) is expressed in amphioxus neurons. Zoolog Sci (2009) 26:409-14. doi:10.2108/zsj.26.409

46. Larsen D, Swanson P. Effects of gonadectomy on plasma gonadotropins I and II in coho salmon, Oncorhynchus kisutch. Gen Comp Endocrinol (1997) 108:152-60. doi:10.1006/gcen.1997.6958

47. Kobayashi M, Stacey NE. Effects of ovariectomy and steroid hormone implantation on serum gonadotropin levels in female goldfish. Zoolog Sci (1990) 7:715-21.

48. Habibi HR, de Leeuw R, Nahorniak CS, Goos HJ, Peter RE. Pituitary gonadotropin-releasing hormone $(\mathrm{GnRH})$ receptor activity in goldfish and catfish: seasonal and gonadal effects. Fish Physiol Biochem (1989) 7:109-18. doi:10.1007/BF00004696

49. Saligaut C, Linard B, Mananos EL, Kah O, Breton B, Govoroun M. Release of pituitary gonadotropins GtHI and GtHII in the rainbow trout (Oncorhynchus mykiss): modulation by estradiol and catecholamines. Gen Comp Endocrinol (1998) 109:302-9. doi:10.1006/gcen.1997.7033

50. Dickey JT, Swanson P. Effects of sex steroids on gonadotropin (FSH and LH) regulation in coho salmon (Oncorhynchus kisutch). J Mol Endocrinol (1998) 21:291-306. doi:10.1677/jme.0.0210291
51. Kobayashi M, Sohn YC, Yoshiura Y, Aida K. Effects of sex steroids on the mRNA levels of gonadotropin subunits in juvenile and ovariectomized goldfish Carassius auratus. Fish Sci (2000) 66:223-31. doi:10.1046/j.1444-2906.2000. 00038.x

52. Vacher C, Ferrière F, Marmignon MH, Pellegrini E, Saligaut C. Dopamine D2 receptors and secretion of FSH and LH: role of sexual steroids on the pituitary of the female rainbow trout. Gen Comp Endocrinol (2002) 127:198-206. doi:10.1016/S0016-6480(02)00046-1

53. Levavi-Sivan B, Biran J, Fireman E. Sex steroids are involved in the regulation of gonadotropin-releasing hormone and dopamine D2 receptors in female tilapia pituitary. Biol Reprod (2006) 75:642-50. doi:10.1095/biolreprod.106.051540

54. Banerjee A, Khan I. Molecular cloning of FSH and LH $\beta$ subunits and their regulation of estrogen in Atlantic croaker. Gen Comp Endocrinol (2008) 155:827-37. doi:10.1016/j.ygcen.2007.09.016

55. Huggard-Nelson DL, Nathwani PS, Kermouni A, Habibi HR. Molecular characterization of LH-beta and FSH-beta subunits and their regulation by estrogen in the goldfish pituitary. Mol Cell Endocrinol (2002) 188:171-93. doi:10.1016/ S0303-7207(01)00716-X

56. Aroura S, Weltzien F-A, Belle NL, Dufour S. Development of real-time RT-PCR assays for eel gonadotropins and their application to the comparison of in vivo and in vitro effects of sex steroids. Gen Comp Endocrinol (2007) 153:333-43. doi:10.1016/j.ygcen.2007.02.027

57. Huggard D, Khakoo Z, Kassam G, Mahmoud SS, Habibi HR. Effect of testosterone on maturational gonadotropin subunit messenger ribonucleic acid levels in the goldfish pituitary. Biol Reprod (1996) 54:1184-91. doi:10.1095/ biolreprod54.6.1184

58. Nozaki M, Uchida K, Honda K, Shimotani T, Nishiyama M. Effects of Estradiol or testosterone treatment on expression of gonadotropin subunit mRNAs and proteins in the pituitary of juvenile brown hagfish, Paramyxine atami. Gen Comp Endocrinol (2013) 189:142-50. doi:10.1016/j.ygcen.2013.04.034

59. Schützinger S, Choi HS, Patzner RA, Adam H. Estrogens in plasma of the hagfish, Myxine glutinosa (Cyclostomata). Acta Zool (Stockh) (1987) 68:263-6. doi:10.1111/j.1463-6395.1987.tb00893.x

60. Powell ML, Kavanaugh S, Sower SA. Seasonal concentrations of reproductive steroids in the gonads of the Atlantic hagfish, Myxine glutinosa. J Exp Zool (2004) 301A:352-60. doi:10.1002/jez.a.20043

61. Powell ML, Kavanaugh SI, Sower SA. Current knowledge of hagfish reproduction: implications for fisheries management. Integr Comp Biol (2005) 45:158-65. doi:10.1093/icb/45.1.158

62. Nishiyama M, Chiba H, Uchida K, Shimotani T, Nozaki M. Relationships between plasma concentrations of sex steroid hormones and gonadal development in the brown hagfish, Paramyxine atami. Zoolog Sci (2013) 30:967-74. doi:10.2108/zsi.30.967

63. Yu JYL, Dickhoff WW, Swanson P, Gorbman A. Vitellogenesis and its hormonal regulation in the Pacific hagfish, Eptatretus stouti L. Gen Comp Endocrinol (1981) 43:492-502. doi:10.1016/0016-6480(81)90234-3

64. Lowartz S, Petkam R, Renaud R, Beamish FWH, Kime DE, Raeside J, et al. Blood steroid profile and in vitro steroidogenesis by ovarian follicles and testis fragments of adult sea lamprey, Petromyzon marinus. Comp Biochem Physiol A Mol Integr Physiol (2003) 134:365-76. doi:10.1016/S1095-6433(02)00285-4

65. Young BA, Bryan MB, Glenn JR, Yun SS, Scott AP, Li W. Dose-response relationship of $15 \alpha$-hydroxylated sex steroids to gonadotropin-releasing hormones and pituitary extract in male sea lampreys (Petromyzon marinus). Gen Comp Endocrinol (2007) 151:108-15. doi:10.1016/j.ygcen.2006.12.005

66. Bryan MB, Scott AP, Li W. The sea lamprey (Petromyzon marinus) has a receptor for androstenedione. Biol Reprod (2007) 77:688-96. doi:10.1095/biolreprod. 107.061093

67. Bryan MB, Scott AP, Li W. Sex steroids and their receptors in lampreys. Steroids (2008) 73:1-12. doi:10.1016/j.steroids.2007.08.011

68. Young BA, Bryan MB, Sower SA, Scott AP, Li W. 15 $\alpha$-Hydroxytestosterone induction by GnRH-I and GnRH-III in Atlantic and Great Lakes sea lamprey (Petromyzon marinus L.). Gen Comp Endocrinol (2004) 136:276-81. doi:10.1016/j.ygcen.2003.12.022

69. Hirose K, Tamaoki B, Fernholm B, Kobayashi H. In vitro bioconversions of steroids in the mature ovary of the hagfish, Eptatretus burgeri. Comp Biochem Physiol (1975) 51B:403-8.

70. Kime DE, Hews EA, Gafter J. Steroid biosynthesis by testes of the hagfish $M y x-$ ine glutinosa. Gen Comp Endocrinol (1980) 41:8-13. doi:10.1016/0016-6480(80) 90026-X 
71. Kime DE, Hews EA. Steroid biosynthesis by the ovary of the hagfish Myxine glutinosa. Gen Comp Endocrinol (1980) 42:71-5. doi:10.1016/0016-6480(80)90258-0

72. Adams BA, Tello JA, Erchegyi J, Warby C, Hong DJ, Akinsanya KO, et al. Six novel gonadotropin-releasing hormones are encoded as triplets on each of two genes in the protochordate, Ciona intestinalis. Endocrinology (2003) 114:1907-19. doi:10.1210/en.2002-0216

73. Tsai PS, Zhang L. The emergence and loss of gonadotropin-releasing hormone in protostomes: orthology, phylogeny, structure, and function. Biol Reprod (2008) 79:798-805. doi:10.1095/biolreprod.108.070185

74. Zhang L, Tello JA, Zhang W, Tsai PS. Molecular cloning, expression pattern, and immunocytochemical localization of a gonadotropin-releasing hormone-like molecule in the gastropod mollusk, Aplysia californica. Gen Comp Endocrinol (2008) 156:201-9. doi:10.1016/j.ygcen.2007.11.015

75. Staubli F, Jorgensen TJ, Cazzamali G, Williamson M, Lenz C, Sondergarrd L, et al. Molecular identification of the insect adipokinetic hormone receptors. Proc Natl Acad Sci USA (2002) 99:3446-51. doi:10.1073/pnas.052556499

76. Lindemans M, Liu F, Janssen T, Husson SJ, Mertens I, Gade G, et al. Adipokinetic hormone signaling through the gonadotropin-releasing hormone receptor modulates egg-laying in Caenorhabditis elegans. Proc Natl Acad Sci USA (2009) 106:1642-7. doi:10.1073/pnas.0809881106

77. Lindemans M, Jannsen T, Beets I, Temmerman L, Meelkop E, Schoofs L. Gonadotropin-releasing hormone and adipokinetic hormone signaling systems share a common evolutionary origin. Front Endocrinol (2011) 12:16 doi:10.3389/fendo.2011.00016

78. Osugi T, Uchida K, Nozaki M, Tsutsui K. Characterization of novel RFamide peptides in the central nervous system of the brow hagfish: isolation, localization, and functional analysis. Endocrinology (2011) 152:4252-64. doi:10.1210/ en.2011-1375
79. Tsukahara T, Gorbman A, Kobayashi H. Median eminence equivalence of the neurohypophysis of the hagfish, Eptatretus burgeri. Gen Comp Endocrinol (1986) 61:348-54. doi:10.1016/0016-6480(86)90220-0

80. Gorbman A. Olfactory origins and evolution of the brain-pituitary endocrine system: facts and speculation. Gen Comp Endocrinol (1995) 97:171-8. doi:10. 1006/gcen.1995.1016

81. Janvier P. Early Vertebrates. Oxford: Clarendon Press (1996).

82. Nozaki M, Gorbman A. Immunocytochemical localization of somatostatin and vasotocin in the brain of the Pacific hagfish, Eptatretus stouti. Cell Tissue Res (1983) 229:541-50.

Conflict of Interest Statement: The author declares that the research was conducted in the absence of any commercial or financial relationships that could be construed as a potential conflict of interest.

Received: 26 November 2013; accepted: 17 December 2013; published online: 30 December 2013.

Citation: Nozaki M (2013) Hypothalamic-pituitary-gonadal endocrine system in the hagfish. Front. Endocrinol. 4:200. doi: 10.3389/fendo.2013.00200

This article was submitted to Experimental Endocrinology, a section of the journal Frontiers in Endocrinology.

Copyright (C) 2013 Nozaki. This is an open-access article distributed under the terms of the Creative Commons Attribution License (CC BY). The use, distribution or reproduction in other forums is permitted, provided the original author(s) or licensor are credited and that the original publication in this journal is cited, in accordance with accepted academic practice. No use, distribution or reproduction is permitted which does not comply with these terms. 